\title{
THE EFFECT OF STRAIN AND TEMPERATURE PROFILES ON STATIC RECRYSTALLIZATION DURING SOLUTION HEAT TREATMENT AFTER HOT DEFORMATION OF ALLOY 718
}

\author{
Richard Watson ${ }^{1}$, Michael Preuss ${ }^{1}$, João Quinta da Fonseca ${ }^{1}$, Thomas Witulski ${ }^{2}$, Gregor \\ Terlinde $^{2}$ \\ ${ }^{1}$ University of Manchester, School of Materials, Grosvenor Street, Manchester, M1 7HS, UK. \\ ${ }^{2}$ Otto Fuchs KG, Abt. 05/2, Derschlager str. 26, 58540, Meinerzhagen, Germany.
}

Keywords: Thermomechanical processing, Microstructure Evaluation, EBSD, Recrystallization

\begin{abstract}
An investigation into the effect of temperature and strain gradients on recrystallization during solution heat treatment has been performed on Alloy 718 test pieces. High temperature compression experiments were carried out using a Gleeble, which generates strain and temperature gradients within the compression sample. The initial results have shown there is a band in the deformation transition zone where large abnormally coarse grains manifest after solution heat treatment. Detailed analysis by Electron Backscatter Diffraction (EBSD) was carried out to determine grain characteristics as well as $\delta$ phase distribution and morphology. Grains produced via this abnormal grain coarsening are characterised by a large percentage of twin boundaries. The grain growth also appears to be immune to the effects of boundary pinning by $\delta$ phase particles. The results suggest that stored energy gradients may be the key to this phenomenon.
\end{abstract}

\section{Introduction}

During a trial forging of an Alloy 718 component Otto Fuchs AG observed an abnormally coarse microstructure that was not predicted by current recrystallization models [1]. These abnormal grains appeared after the solution heat treatment (SHT). Abnormally coarse grains are problematic in disc alloys as they can negatively impact the fatigue performance of components made from them. This was shown by Flageolet et al in an investigation into the effects of sporadic abnormally coarse grains on Low Cycle Fatigue (LCF) performance on Alloy 718 at $350^{\circ} \mathrm{C}[2]$. When these microstructures occur the usual practice is to scrap the component and retool the dies to change the shape that the part is deformed into, leading to reduced yield and increased production times and costs.

The abnormal microstructures appear to contain a high proportion of annealing twin boundaries [1], similar to those found in strain annealed steels [2-4]. However there are some fundamental differences between the conditions under which these microstructures are formed. In austenitic steels specimens are usually cold rolled before annealing whereas in the Alloy 718 forging the microstructures were formed by hot working and annealing. Strain annealing is performed in the solution heat treated condition and hence in the absence of carbide particles that can pin grain boundaries. In contrast, Alloy 718 contains second phase particles when solution heat treated below the $\delta$ solvus that should prevent grain coarsening. Some characterisation of the phenomenon in Alloy 718 showed that abnormally coarse regions contained 66\% twin 
boundaries compared with $24 \%$ for the normal regions, and that the abnormally coarse region is characterized by low levels of stored energy [1].

Recent work by Bozzolo et al has shown that, in low strain situations, some stored energy driven growth can occur in both Alloy 718 and Udimet 720 [6]. These microstructures were also reported to have higher proportions of annealing twin boundaries. Studies suggest that in order to get a highly twinned microstructure you need a situation where the strain is low.

In an effort to shed light on the formation of these abnormal grain structures hot compression tests using a Gleeble 3500 where performed in order to induce temperature and strain gradients into the test piece. These test pieces were then investigated in both the as deformed and heat treated state and characterised using backscatter electron (BSE) imaging and EBSD.

\section{Experimental Procedure}

Cylinders of $13 \mathrm{~mm}$ diameter by $95 \mathrm{~mm}$ length were EDM machined from a piece of billet material, which were taken from a radial position of $20 \mathrm{~mm}$ from the edge of the billet. The samples were machined further down to $10 \mathrm{~mm}$ diameter by $15 \mathrm{~mm}$ length compression samples. Thermocouples were attached to the sample according to Figure 1 with one control thermocouple in the centre and two thermocouples being placed 1-2 $\mathrm{mm}$ from the tungsten carbide platens. An additional thermocouple was placed on the platen to provide data about potential die chill effects and its position is also shown in Figure 1.

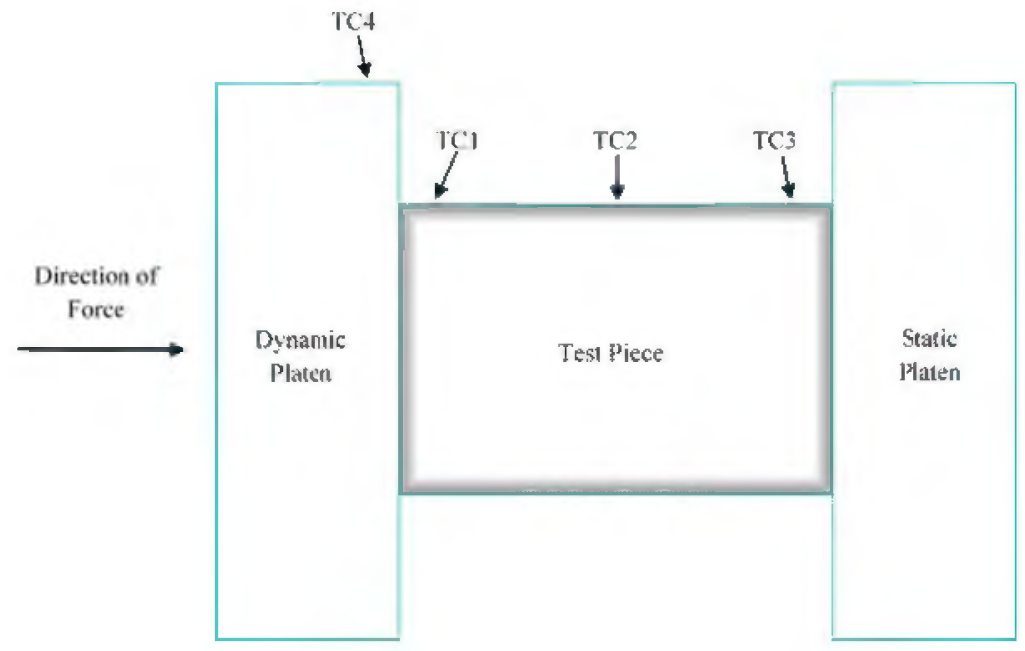

Figure 1. Experimental set up showing the locations of the thermocouples (TC) on the test piece and platen

A Gleeble 3500 was used to compress the samples to crosshead strains of 0.15 and 0.25 at two different temperatures below the $\delta$ solvus $\left(\mathrm{T}_{2}=\mathrm{T}_{1}+20^{\circ} \mathrm{C}\right)$ for strain rates of $0.01 \mathrm{~s}^{-1}, 0.1 \mathrm{~s}^{-1}$ and $1 \mathrm{~s}^{-1}$. The heating and cooling cycles were both conducted within 2 minutes to avoid precipitation of second phase particles. Samples were held for 1 minute at the deformation temperature to allow the temperature to stabilize in the centre of the test piece before the compression test commenced. Subsequently, the compression test pieces were cut in half in order to subject one half to a 1 hour solution heat treatment below the $\delta$-solvus temperature

The metallographic preparation first started with grinding down $250 \mu \mathrm{m}$ from the flat surface of the heat treated samples to remove any surface effects. Both halves were ground, diamond 
polished and further polished with colloidal silica suspension (OPS) in preparation for BSE imaging and EBSD. Backscattered images were taken at a working distance of $6 \mathrm{~mm}$ to give an orientation contrast. After initial screening of the samples using BSE, the as deformed and subsequently solution heat treated halves of conditions that had resulted in abnormal microstructure were further analysed by EBSD for more detailed characterisation. Two types of EBSD scans were carried out. Firstly, large area EBSD was undertaken over the detected transition zone at a working distance of $10 \mathrm{~mm}$ with acceleration voltage of $20 \mathrm{kV}$ and step size of $0.5 \mu \mathrm{m}$. In addition, EBSD analysis with a higher spatial resolution was conducted at a working distance of $10 \mathrm{~mm}$. The increased spatial resolution was achieved by choosing an acceleration voltage of $15 \mathrm{kV}$, which results in an interacting volume slightly smaller than $200 \mathrm{~nm}$ [7] in combination with a step size of $0.2 \mu \mathrm{m}$.

Test piece simulations were produced from the experimental data obtained during the Gleeble tests and dimensions taken from the test pieces using DEFORM 2D utilising material data for Alloy 718 provided by Otto Fuchs AG. The DEFORM 2D model is required to fully understand the deformation occurring in the test piece. Gleeble test pieces often end up slightly barrelled because the testing method is not isothermal and frictional effects with the platens mean that samples will not deform uniformly.

\section{Results}

The average temperature difference for the Gleeble tests between the outer and controlling central thermocouple was recorded to be about $60^{\circ} \mathrm{C}$. The platen temperature was in average about $200^{\circ} \mathrm{C}$ lower than the test temperature at the centre axial position of the sample.

Figure 2 shows a model with approximate strain and temperature gradients expected within the test piece. The data for the model was collected from physical measurements of the external deformation observed in the samples as well as temperature data recorded during the experiments. The thermal gradient was found to be localised to the ends of the test piece. During testing it was ascertained that if the thermocouple was placed at a distance greater than $3 \mathrm{~mm}$ from the platen it would show the same temperature as the centre of the test piece.
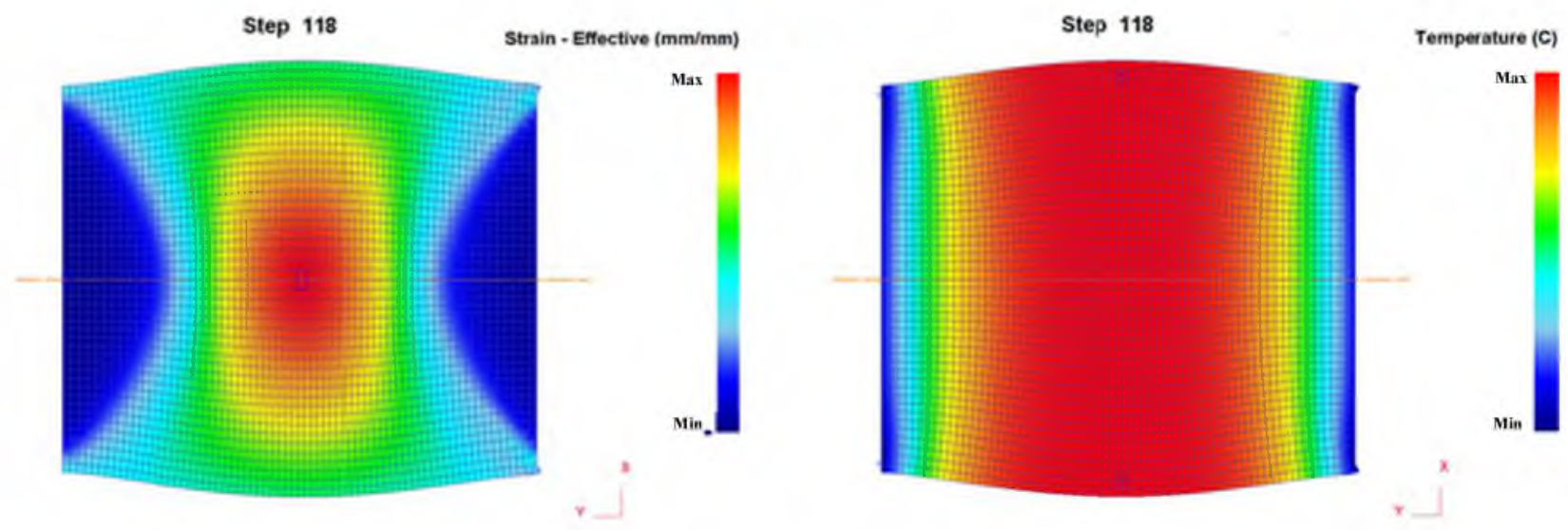

Figure 2: Typical strain distribution and temperature profile calculated in DEFORM 2D 


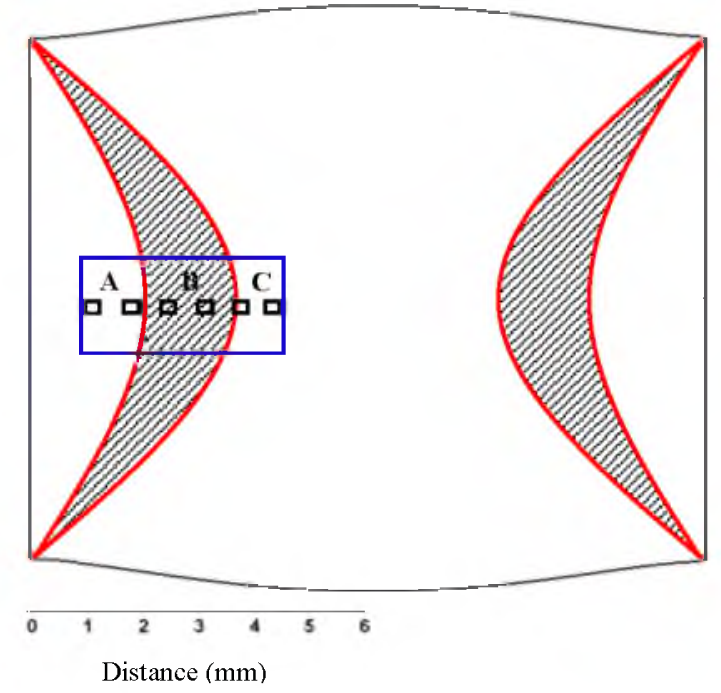

Figure 3: Diagram of a typical deformed Gleeble test piece. Areas bounded by red show where abnormal grains are usually observed. The blue box represents the investigation area. The black boxes indicate the approximate locations of the higher resolution EBSD.

The screening process using BSE imaging revealed that the samples showed in 10 out of 12 cases three distinct regions, schematically presented in Figure 3. Figure 4 shows an overview $\mathrm{BSE}$ image, which displays the nature of region $\mathrm{A}, \mathrm{B}$ and $\mathrm{C}$. Region $\mathrm{A}$ shows an area where no recrystallization of the billet grain structure appears to have taken place and grain boundaries are still firmly pinned by the $\delta$ phase particles. Region B shows an abnormally coarse microstructure in which the grains were not pinned by the $\delta$ phase particles, which are now intragranular. In addition, the coarse microstructure has become highly twinned, which makes identification of individual grains rather difficult. Region $\mathrm{C}$ shows a finer region than region $\mathrm{B}$ but coarser than region $\mathrm{A}$.

Figure 5 shows the transition zone between the billet microstructure and the abnormally coarse microstructure. What can be observed are large grains containing a high proportion of twins. Found within these grains are $\delta$ phase particles that appear to describe a ghost microstructure from the previous condition.

Further backscatter images were taken every $500 \mu \mathrm{m}$, starting at the centre of the sample, to perform a grain size analysis using linear intercept method. There was very little indication of a correlation between changes in microstructure with change in temperature, strain or strain rate. In general, the abnormally coarse structure occurs at a depth of $2-3 \mathrm{~mm}$ from the end of the sample except for two samples. Figure 6 shows the grain size evolution for sample 7 which had been strained to 0.15 at $\mathrm{T}_{2}$, as an example of how the grain size changes within a test piece

Figure 7 shows average grain misorientation and grain boundary maps of the transition zone produced from EBSD scans performed on sample 7. Figure 7 (a) and (c) are maps prior to heat treatment and (b) and (d) are post heat treatment. The maps start at $1.6 \mathrm{~mm}$ from the edge of the sample and are $1.4 \mathrm{~mm}$ wide finishing at a depth of $3 \mathrm{~mm}$ (see blue box in Figure 3 ). The average misorientation analysis in Figure 7 (a) and (b) gives an indication on how much the 


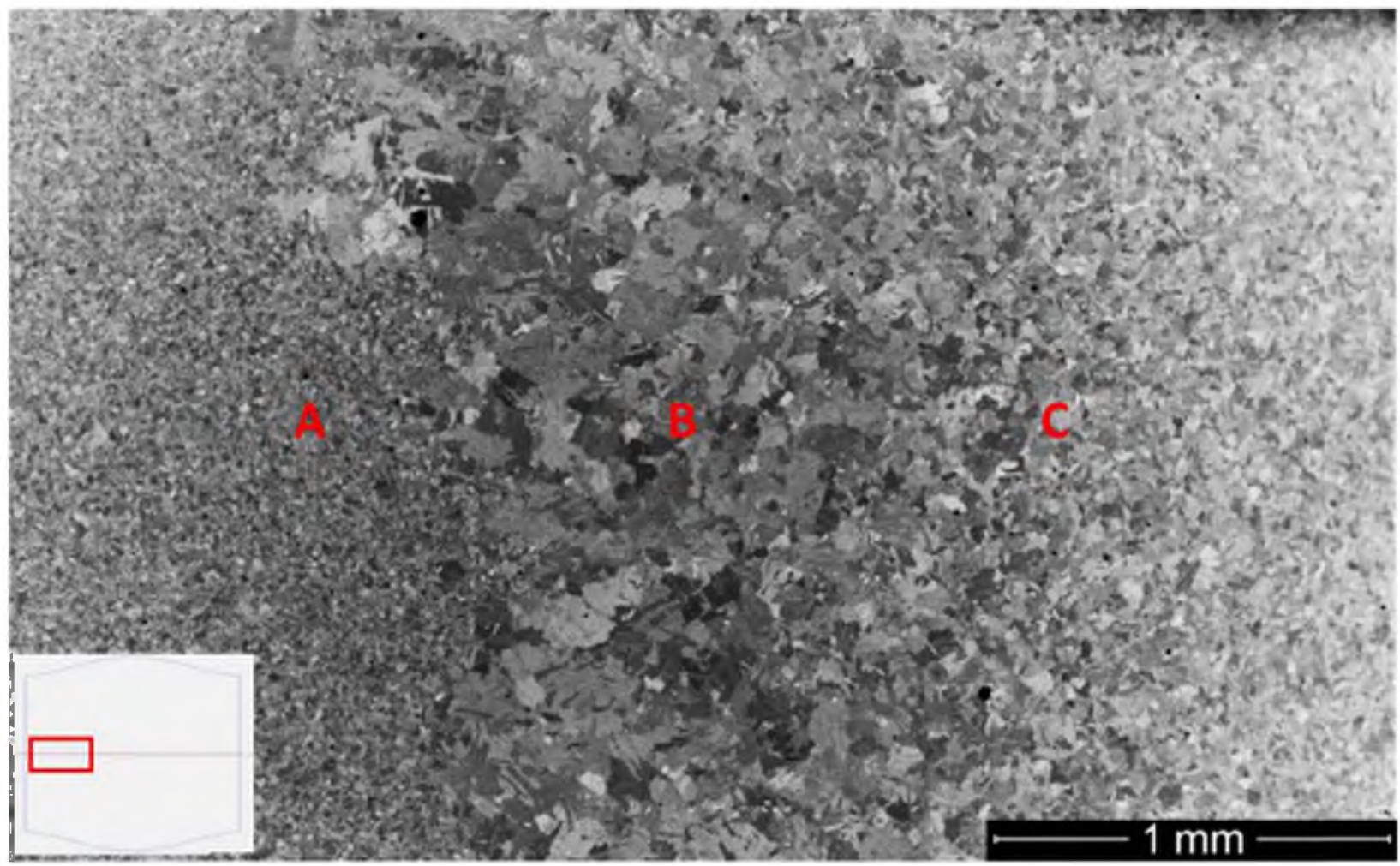

Figure 4: BSE image of the transition region in the sample tested to $\varepsilon=0.25$ at $\mathrm{T}_{1}$. $\mathrm{A}$ is representative of a microstructure typically found in the starting billet material, $\mathrm{B}$ is an abnormally coarse region and $\mathrm{C}$ signifies the start of what is considered to be a normal fully recrystallized equiaxed microstructure.

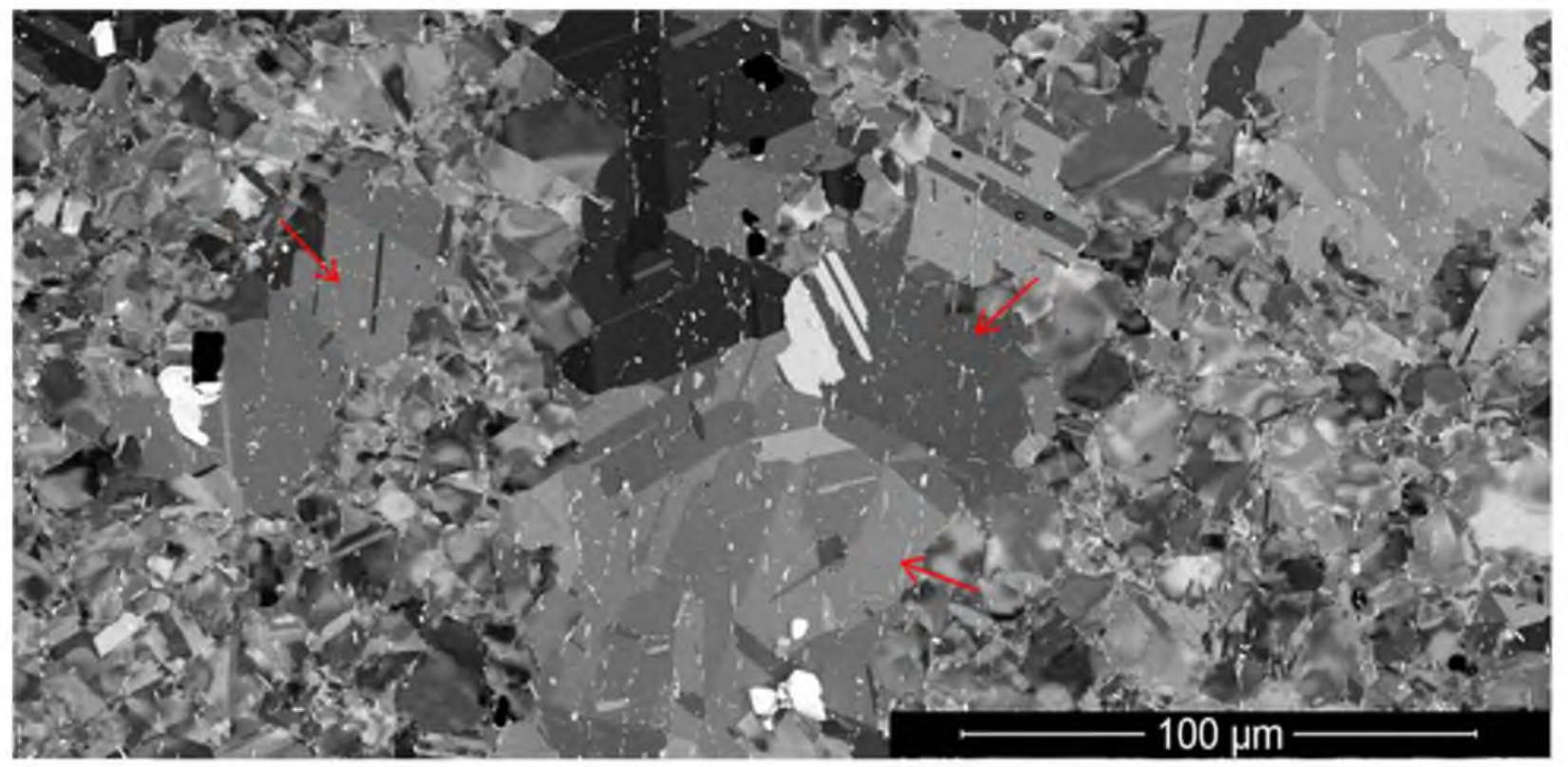

Figure 5: Close up of the transition region between billet and abnormally coarse microstructure. $\delta$ phase can clearly be seen to be intragranular and annealing twins can be observed throughout the grains. The red arrows point to $\delta$ phase particles that appear to show a ghost microstructure from the previous condition. 
orientation changes over the surface of a grain. An orientation change across a grain can be linked directly to the stored energy in the material. The grain boundary maps in Figure 7 (c) and (d) display twin boundaries in red, non-specified high angle grain boundaries in black and low angle grain boundaries in grey.

Figure 7 (a) shows that from left (platen) to right (towards centre) there is an increasing amount of grains with a high proportion of average grain misorientation. After heat treatment, Figure 7 (b), there is a region towards the platen that has clearly not changed during the heat treatment whereas towards the centre region of the sample (right) a substantial decrease in average grain misorientation can be seen. Figure 7 (c) and (d) describes a dramatic change in the microstructure post heat treatment, showing a considerable amount of coarsening and increase in proportion of twins within the centre region. It is also noticeable that Figure 7 (c) shows a larger proportion of low angled grain boundaries (LAGBs), denoted by the grey lines than Figure 7 (d). This helps contribute to lower average grain misorientation values on the left hand side of the average grain misorientation plot.

Figure 3 shows the chosen locations for the higher resolution EBSD scans. These scans were taken at $300 \mu \mathrm{m}$ intervals across the transition zone to investigate any small microstructural changes within the investigation area. Figure 8 shows higher resolution average misorientation maps taken at increasing distance from the platen. As the scans go deeper into the sample two observations can be made. The mean average misorientation in a grain changes with depth and the number of grains with average misorientation between $0^{\circ}$ and $1^{\circ}$ also changes inversely to that of the mean average grain misorientation value as shown in Figure 9. The region where abnormal grain coarsening is expected is between $2-3 \mathrm{~mm}$ from the samples edge. At these depths the maps reveal that the microstructure contains the highest values of bulk average grain misorientation and lowest amount of grains with misorientation between $0^{\circ}$ and $1^{\circ}$.

\section{Discussion}

Thermocouple measurements showed that there was a temperature gradient across the test pieces in all tests. This is to be expected as the platen is cooler than the test piece. Further to this, when measurements of the sample ends were taken it was found that very little deformation occurred leading to a slight barrelling in the sample. Barrelling, however, is not just a product of temperature gradients and can be caused by frictional effects. Lubricant was used between the platen and test pieces to reduce this but it is likely that friction was not totally eliminated for these tests.

From the measurements from the test pieces a DEFORM model was produced to try and understand what happens to the strain distribution within a sample when this barrelling occurs. The DEFORM model shows that if a temperature gradient exists material near the platen will deform significantly less. This is a common occurrence in forgings having been well documented and is usually known as die chill [8]. This coupled with friction effects leads to strain gradients within the test piece. Figure 2 shows that the temperature profile and strain profile differ leading to a complex strain and temperature state across the sample making it very difficult to isolate a range of parameters that can be used to predict the occurrence of the abnormal microstructure.

What is of interest is the microstructures that form within these transition zones. The backscatter image shown in Figure 4 shows three distinct zones, A, B and C. The grain size analysis of the BSE images failed to find a link between strain, strain rate, temperature with the size of the 


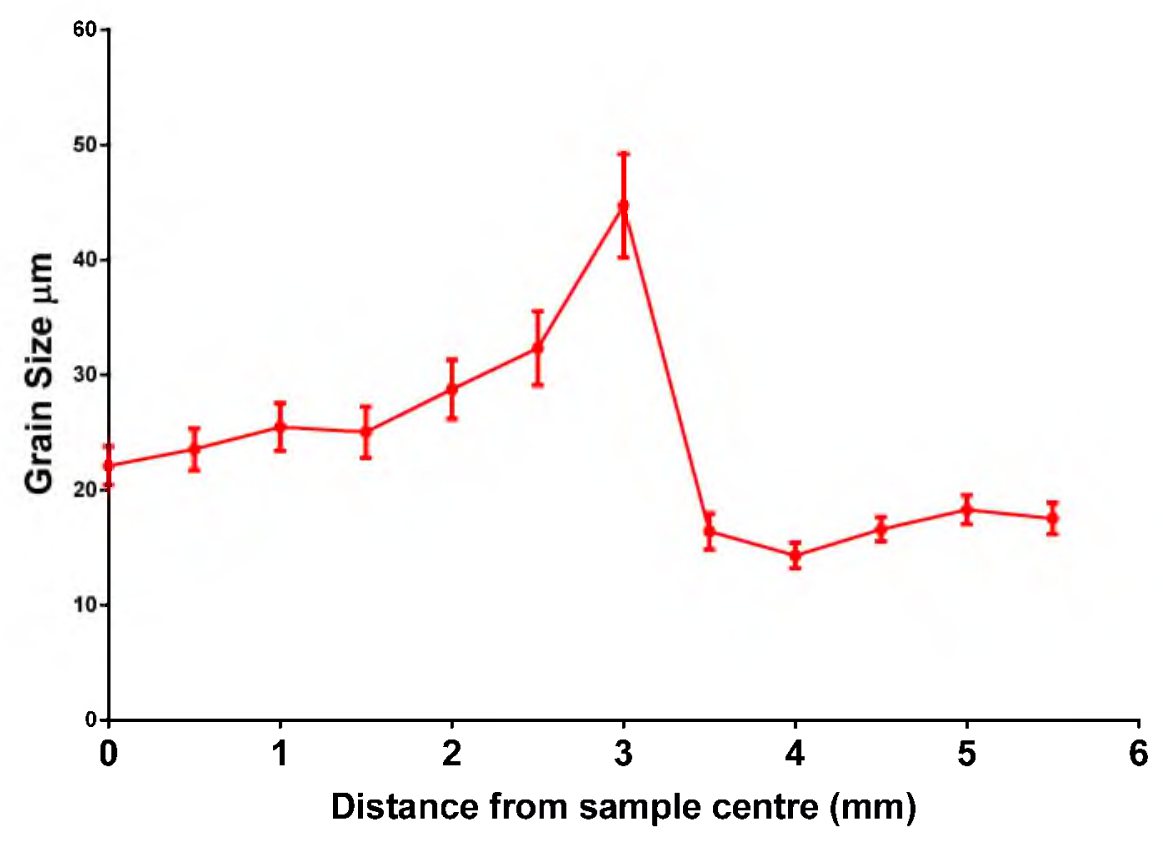

Figure 6: Grain size analysis on sample 7 starting at the sample centre and finishing at the end for crosshead strain of 0.15 and deformation temperature $\mathrm{T}_{2}$,

grains found in abnormally coarse microstructures. This can again probably be attributed to the complex strain state across the sample. Typically if an abnormal region was found to occur it would be at a distance of $2-3 \mathrm{~mm}$ from the platen. At this distance there appears to be a change in deformation behaviour, though the exact conditions remain unclear.

The microstructure found within region $\mathrm{A}$ is identical to the billet material that forms the test pieces. It is not unusual for there to be some stored energy within the microstructure of the billet material and this is often taken into account in industrial forging simulations. Despite the stored energy this is a very stable microstructure and the grains will stay the same size for extended periods of time at temperatures up to the $\delta$ solvus at approximately $1000^{\circ} \mathrm{C}$. This was confirmed by the maps presented in Figure 7 where no real change in grain size was seen. The only observable difference between the prior microstructure during the solution heat treatment is a reduction in the proportion of LAGBs and therefore mean average grain misorientation, indicating that some recovery has taken place.

According to the DEFORM model in Figure 2 little to no strain has occurred in region A, effectively meaning that the material only underwent a thermal cycle to sub $\delta$ solvus temperatures. The average grain misorientation maps at 1.5 and $1.8 \mathrm{~mm}$ in the sample prior to solution heat treatment show that little to no deformation has taken place. The high values of grains with misorientations between $0^{\circ}$ to $1^{\circ}$ can be attributed to a lack of deformation rather than new grains formed by recrystallization.

The abnormally coarse grains are found in region B in Figure 4. According to the DEFORM model this is where the material has been strained over an increasing non uniform temperature and strain gradient. In terms of microstructure, prior to solution heat treatment region B shows a 


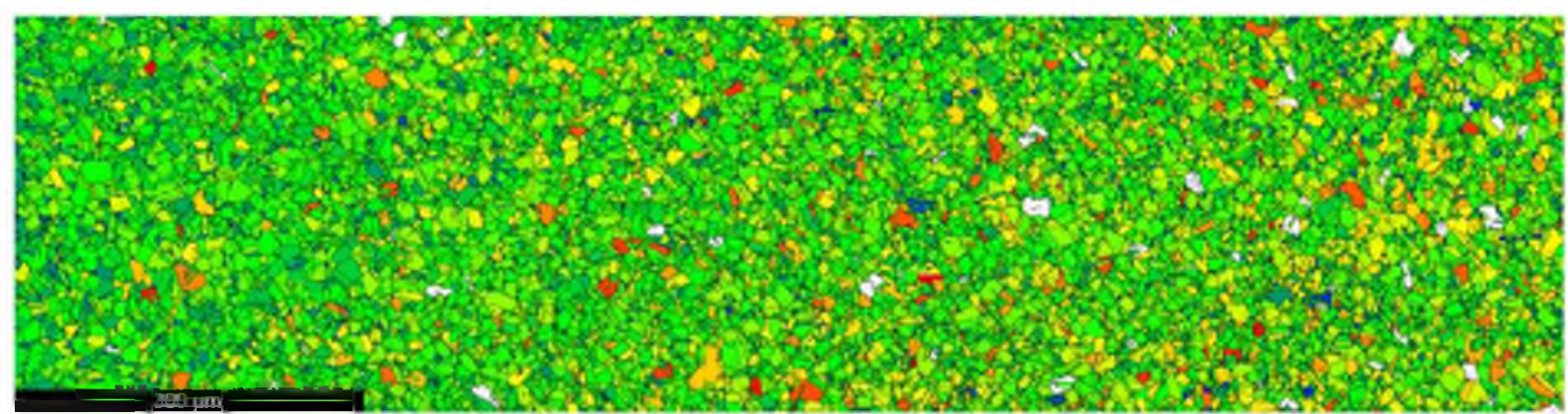

(a)

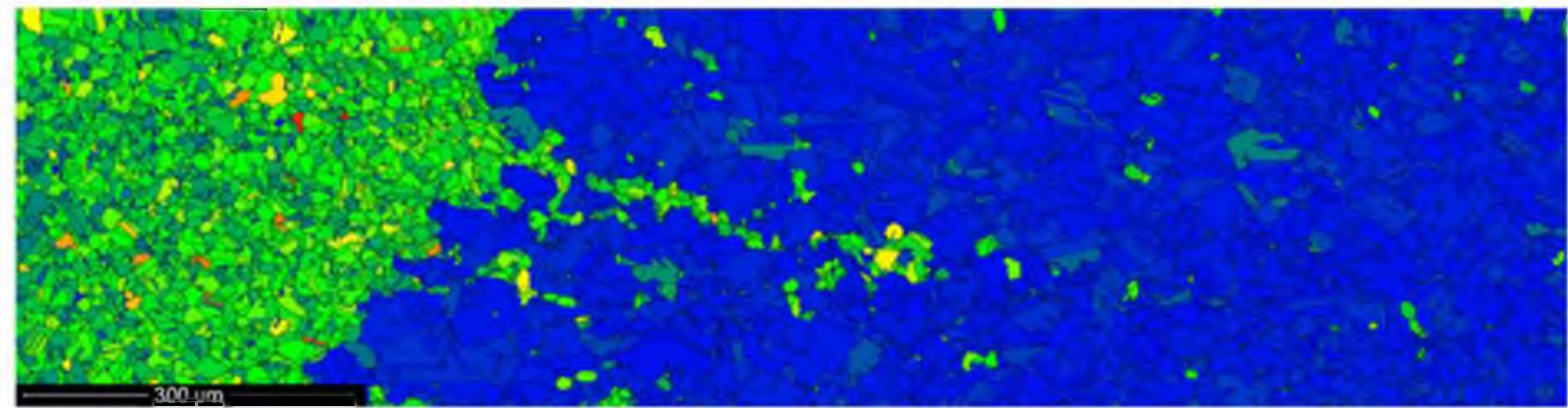

(b)
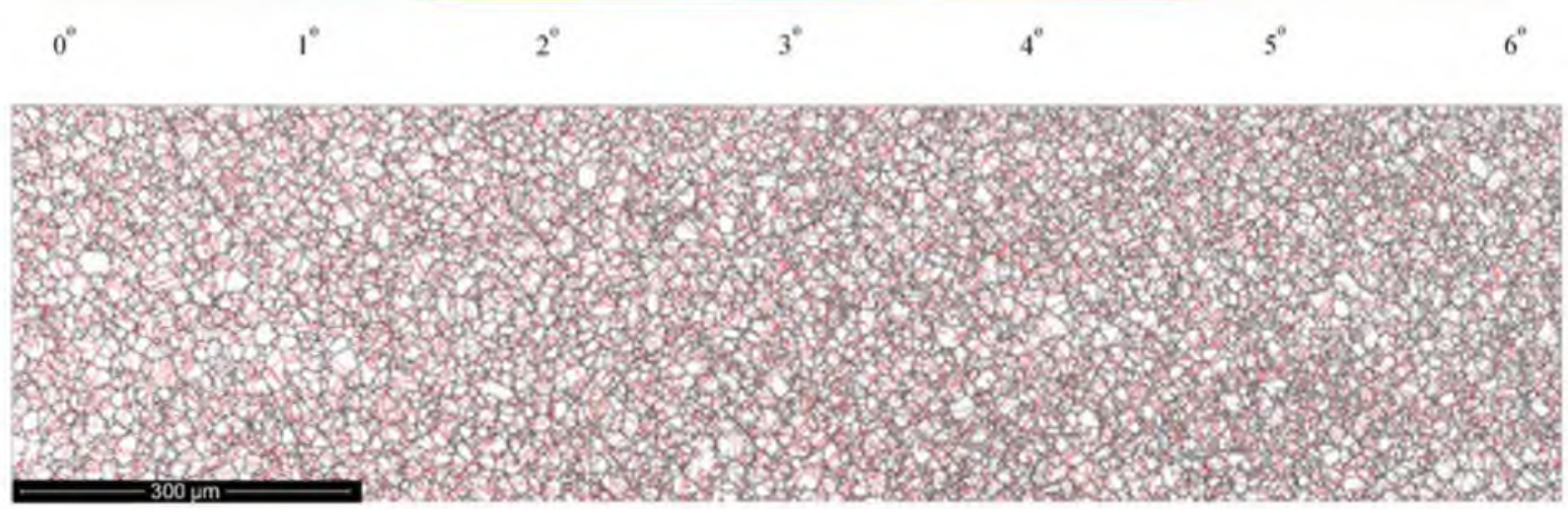

(c)

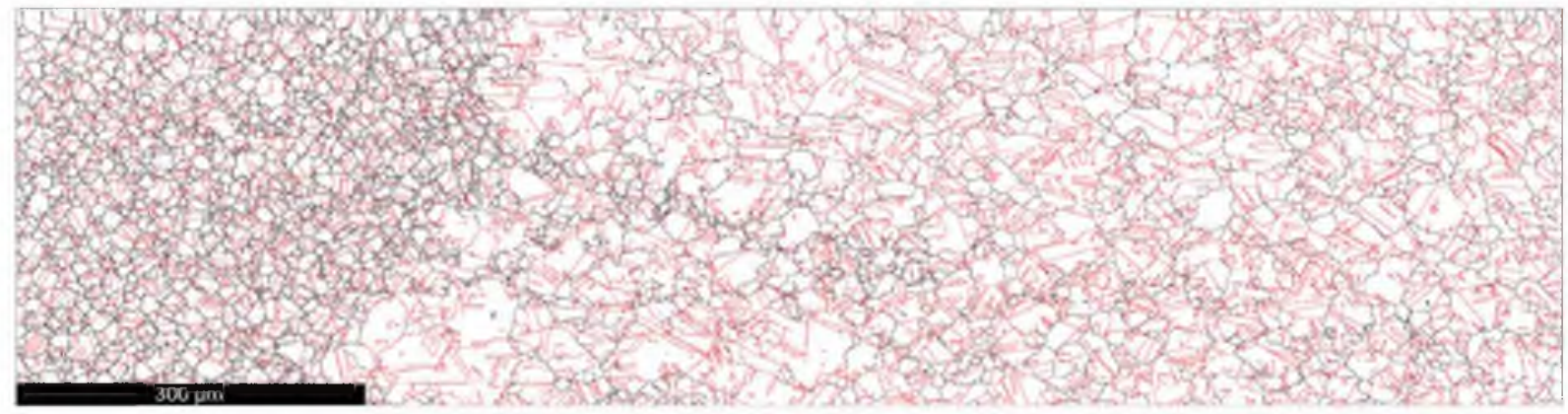

(d)

Figure 7: Plots from EBSD data of (a) Average grain misorientation in the investigated zone in the as deformed state where the white grains have values greater than $6^{\circ}$. In this case they have been ignored as they are the result of incorrect grain reconstruction where two grains have been counted as one. (b) Average grain misorientation in the investigated zone post solution heat treatment. (c) Shows HAGBs and twin boundaries before heat treatment and (d) shows HAGBs and twins post heat treatment. 


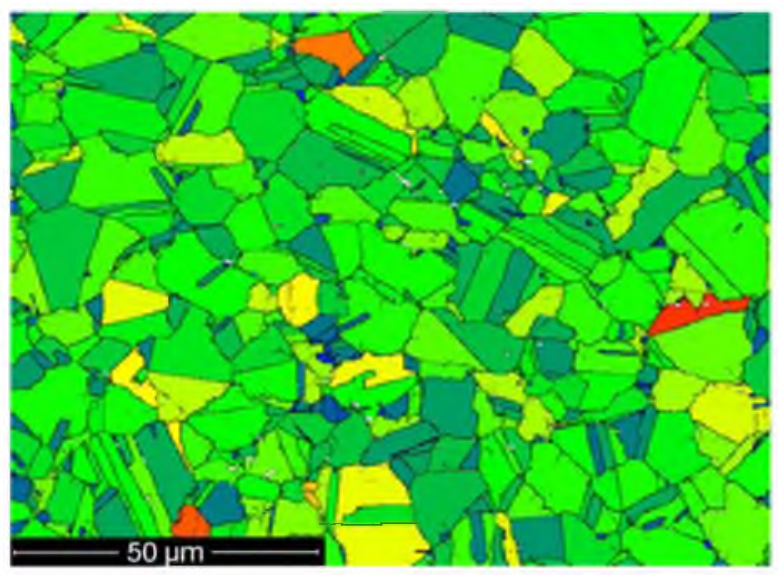

(a) $1.5 \mathrm{~mm}$

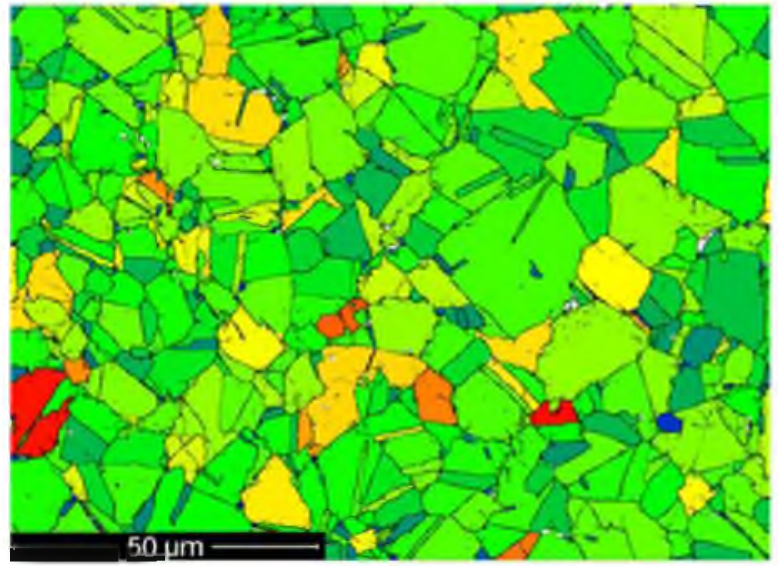

(c) $2.1 \mathrm{~mm}$

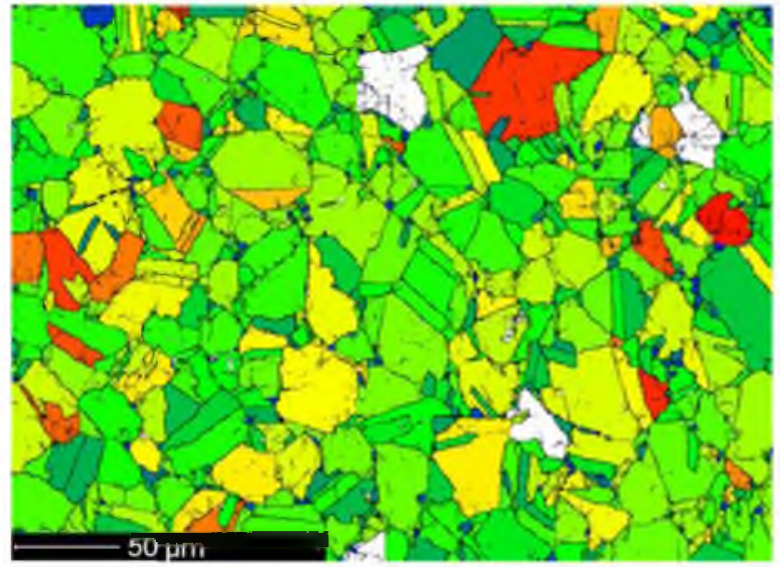

(e) $2.7 \mathrm{~m}$

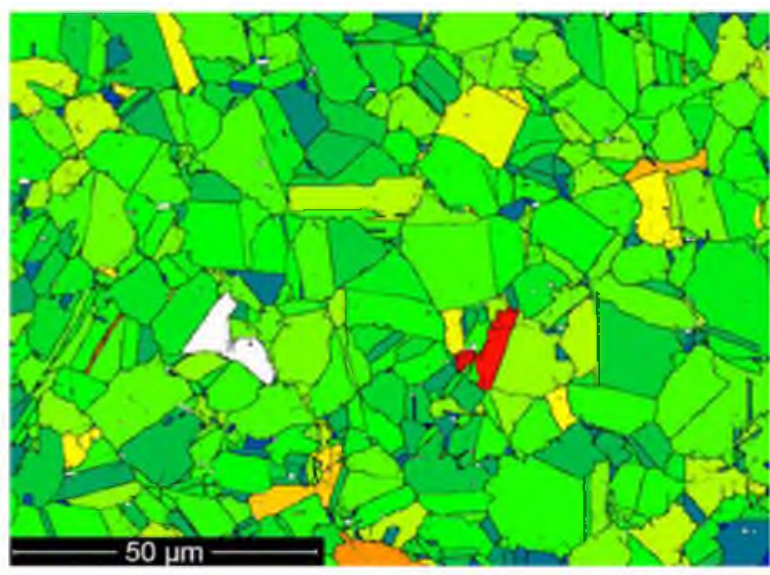

(b) $1.8 \mathrm{~mm}$

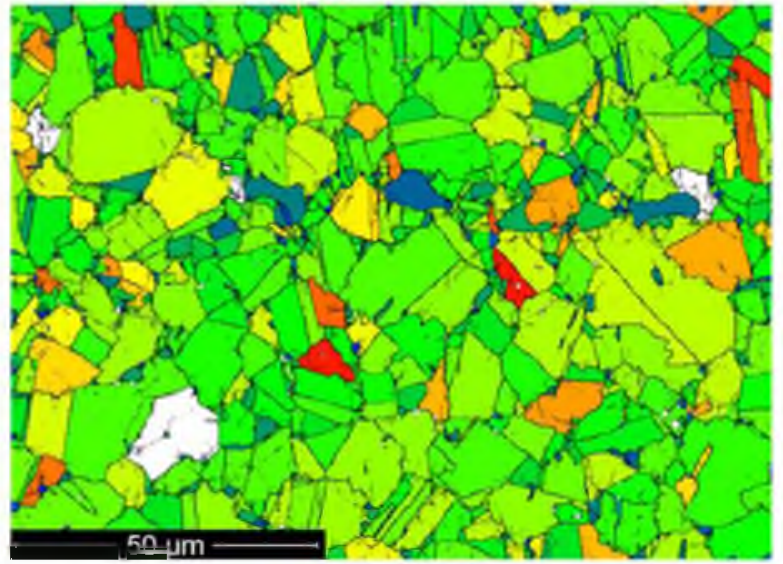

(d) $2.4 \mathrm{~mm}$

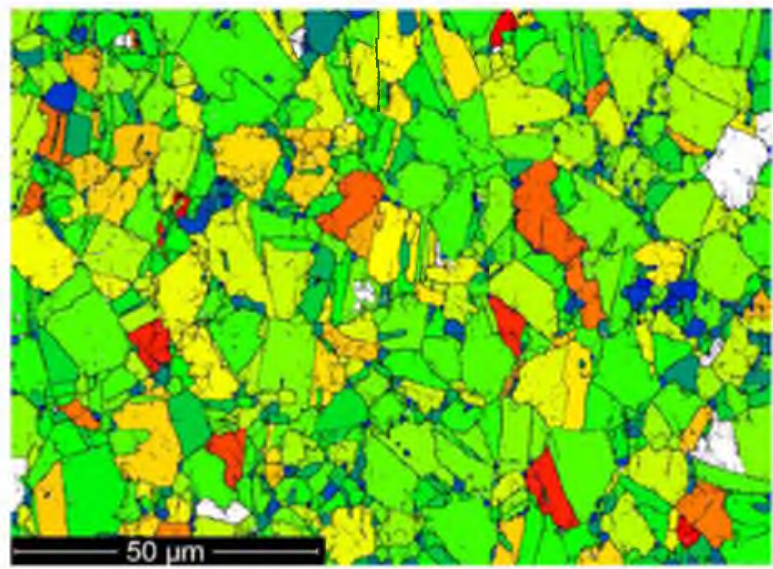

(f) $3.0 \mathrm{~mm}$

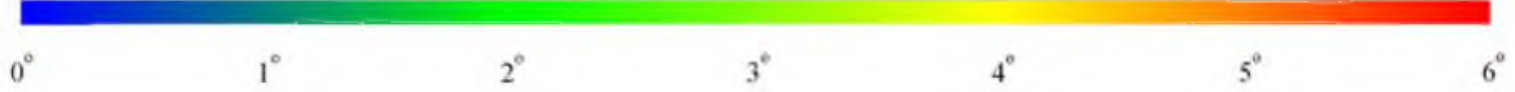

Figure 8: Higher resolution EBSD scans showing average grain misorientation results at different points throughout the investigated zone in the as deformed state. 

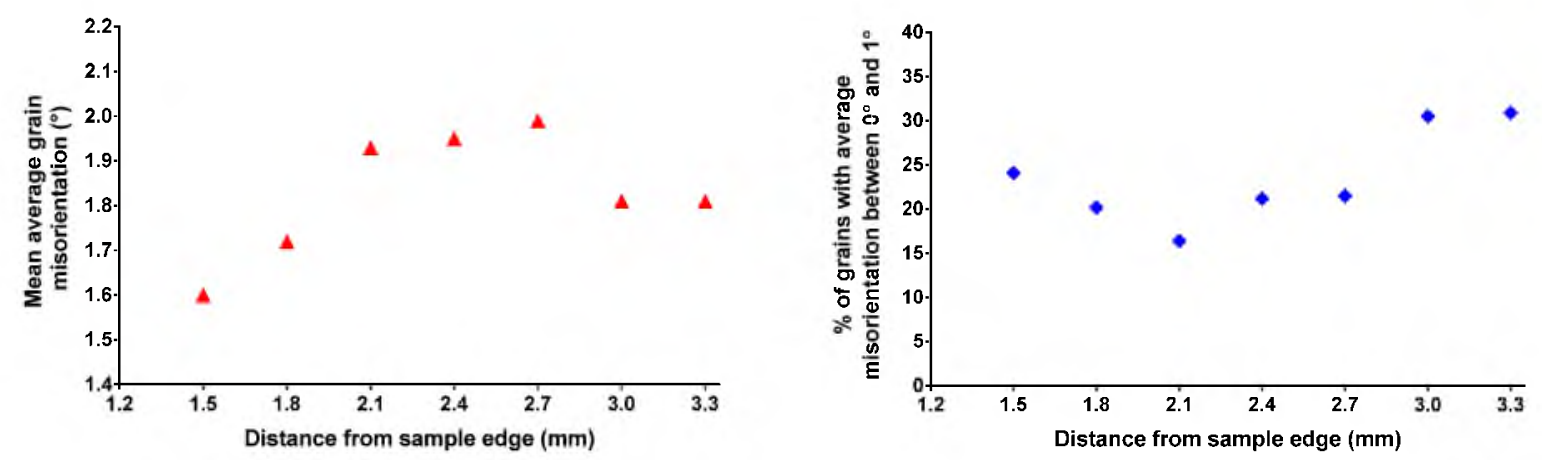

Figure 9: Data taken from the average grain misorientation plots produced from the EBSD data showing (a) mean average grain misorientation for the EBSD map at specified points in the area of investigation and (b) percentage of grains with misorientation between $0^{\circ}$ and $1^{\circ}$.

high value of mean average grain misorientation and therefore stored energy as well as the lowest proportion of newly dynamically recrystallized grains. This is shown in the average grain misorientation maps of Figure 8 and the mean values in Figure 9 for depths of 2.1, 2.4 and 2.7 $\mathrm{mm}$. In essence, there is a situation of sparsely distributed grains, which have recrystallized sitting between grains with a significant amount of stored energy. Solution heat treating seems to allow the rapid growth of the recrystallized grains at the expense of the heavily deformed grains in order to reduce effectively the energy state in the material. As the distances between the newly formed grains are so great in region B, a large amount of coarsening can occur before a growing grain encounters another new grain stopping grain growth. There is a great deal of work showing that the more deformation that is put into the material the greater the grain refinement is. However the problem here is that a situation has arisen where the grain boundary of a growing grain has enough energy to overcome the pinning force of the $\delta$ phase particles. This can be seen from the grains with intragranular $\delta$ phase in Figure 5. What appears is the deformation process in the abnormally coarse grain region has introduced a large amount of stored energy into the material but in a way where recrystallization and nucleation of new grains does not occur so easily.

The occurrence of a highly twinned microstructure, up to $66 \%$ in abnormal grain size regions, is a direct consequence of rapid grain growth leading to growth accidents at grain boundaries. These lead to the formation of Shockley partial loops that propagate through the grain forming a twin boundary as described in the work by Pande et al [9] and Mahajan et al [10].

Region $\mathrm{C}$ in Figure 4 is representative of a normal equiaxed microstructure. In these regions strain is high and more new grains can form via dynamic and meta-dynamic recrystallization. These small new grains are clearly observable in the average misorientation map of Figure 8. Despite there being significantly more deformation in the large grains, the increase of new small grains serves to lower the mean average grain misorientation and therefore stored energy. This means that although grain growth is fast locally it is not sustained due to the growth being hindered by other growing grains. 


\section{Summary and conclusions}

1. Alloy 718 Samples have been tested at differing strains, strain rates and temperatures in a Gleeble 3500 to see the effect of temperature and strain gradients on Alloy 718 . These tests produced slightly barrelled samples from which a DEFORM 2D model could be created to assess these gradients. During the testing it was found that the majority of the temperature gradient occurred in the first $3 \mathrm{~mm}$ of the test sample. The DEFORM model suggests that where abnormal microstructures occur there is a complex strain and temperature distribution making it difficult to isolate the exact parameters under which they form.

2. Backscatter imaging has revealed the presence of three distinct microstructures within the test piece. Region A, a microstructure identical to that of the starting billet material, region B abnormally coarse microstructures at a depth of $2-3 \mathrm{~mm}$ from the ends of the test piece that has not been successfully pinned by the $\delta$ phase and region $\mathrm{C}$, an area of recrystallized material with gradually reducing grain size. A grain size analysis failed to find any link between strain, strain rate, temperature with coarsened grain size of the abnormal regions.

3. Initial EBSD scans over the transition zone prior to solution heat treatment revealed a reduction in stored energy through both recrystallization and recovery during solution heat treatment. This was achieved through the growth of a coarse highly twinned microstructure and reduction in LAGBs

4. Higher resolution EBSD scans on sample 7 enabled the analysis of the relative proportion of stored energy throughout the investigation area prior to abnormal grains forming. The analysis reveals that in the region B where abnormal grain coarsening occurs there is a low proportion of newly recrystallized grains but relatively high stored energy compared to regions $\mathrm{A}$ and $\mathrm{C}$. This could lead to rapid grain growth and large amounts of grain coarsening due to the sparsely distributed grains not retarding grain growth until they grow into each other. What is unclear is why the $\delta$ phase fails to pin grain boundaries stopping grain growth, though it is likely that the higher amount of stored energy observed in the microstructure prior to heat treatment combined with the relatively high temperature of the solution heat treatment may be to blame. The highly twinned microstructure in the coarse region is attributed to rapid grain growth leading to growth accidents on the advancing grain boundary. 


\section{References}

[1] R. Watson, M. Preuss, J. Quinta, T. Witulski, G. Terlinde, and M. Büscher, "Characterization of Abnormal Grain Coarsening in Alloy 718 .," in EUROSUPERALLOYS 2014, 2014.

[2] B. Flageolet, O. Yousfi, Y. Dahan, P. Villechaise, and J. Cormier, "Characterization of microstructures containing abnormal grain growth zones in Alloy 718," Superalloy 718 Deriv. (7th Int. Symp., pp. 595-606, 2010.

[3] S. Kobayashi, M. Hirata, S. Tsurekawa, and T. Watanabe, "Grain boundary engineering for control of fatigue crack propagation in austenitic stainless steel," Procedia Eng., vol. 10, pp. 112-117, Jan. 2011.

[4] M. Michiuchi, H. Kokawa, Z. J. Wang, Y. S. Sato, and K. Sakai, "Twin-induced grain boundary engineering for 316 austenitic stainless steel," Acta Mater., vol. 54, no. 19, pp. 5179-5184, Nov. 2006.

[5] M. Shimada, H. Kokawa, Z. . Wang, Y. . Sato, and I. Karibe, "Optimization of grain boundary character distribution for intergranular corrosion resistant 304 stainless steel by twin-induced grain boundary engineering," Acta Mater., vol. 50, no. 9, pp. 2331-2341, May 2002.

[6] N. Bozzolo, N. Souaï, R. Logé, A. Agnoli, and M. Bernacki, "Strain induced abnormal grain growth in nickel base superalloys," 5th Int. Conf. Recryst. Grain Growth, pp. 1-4, 2013.

[7] V. Randle and O. Engler, Introduction to texture analysis: macrotexture, microtexture and orientation mapping, 2nd ed. CRC Press, 2010.

[8] N. A. Wilkinson, "Forging of 718 - The Importance of T.M.P.," Superalloy 718 - Metall. Appl., pp. 119-133, 1989.

[9] C. Pande, M. Imam, and B. Rath, "Study of annealing twins in fcc metals and alloys," Metall. Trans. A, vol. 21, no. 11, pp. 2891-2896, 1990.

[10] S. Mahajan, C. Pande, M. Imam, and B. Rath, "Formation of annealing twins in fec crystals," Acta Mater., vol. 45, no. 6, pp. 2633-2638, 1997. 